\title{
DATOS SOBRE EL USO \\ DE LOS PRONOMBRES ÁTONOS \\ DE TERCERA PERSONA EN EL HABLA DE VALENCIA APROXIMACIÓN SOCIOLINGÜÍSTICA
}

\author{
José LuIS Blas ARROYo
}

Universidad Jaume 1. Castellón.

\section{ANTECEDENTES}

La sustitución en español del llamado sistema etimológico en el empleo de los pronombres de tercera persona por otros sistemas ${ }^{1}$ en los que la distinción casual se elude en beneficio de otras diferenciaciones semánticas, funcionales y formales ha despertado un notable interés desde los comienzos de la lingüística científica (Klein, 1981: 284). Los fenómenos de leísmo, laísmo y loismo han sido abordados en numerosas ocasiones por los linguiistas, hasta el punto de que hoy son ya numerosos los datos disponibles para analizar sus causas, así como los principales hitos de su evolución. Así, por ejemplo, y gracias a las aportaciones sucesivas de algunos maestros insignes de la gramática histórica ${ }^{2}$, en la actualidad conocemos con bastante exactitud las principa-

1 Sistemas que habitualmente reciben la denominación de referenciales (vid. KLEIN, 1981: 284; MORENO Y OTROS, 1984: 103).

2 Vease Gessner (1893); Cuervo, R. J. (1895); StaAff (1906); Fernandez, S. (1951); LAPESA (1968); MARCOS (1978). 
les causas que dieron origen al leísmo, fenómeno, como es bien sabido, en torno al cual se encadenaron los demás (Echenique, 1981: 114). Tomando como punto de referencia básico el trabajo liminar de Lapesa (1968), corroborado en lo esencial por investigaciones posteriores (Echenique, 1981; Marcos 1978), existe un relativo consenso en torno a una serie de causas desencadenantes del leísmo en los orígenes del español: 1. paralelismo con otros sistemas pronominales (demostrativos, personales); 2 . homografía proporcionada por la apócope de $l$ ' en el castellano medieval, por influjo de $m^{\prime}$ y $t^{\prime} ; 3$. continuidad del dativo latino regido por determinados verbos ${ }^{3}$ y su difusion a otras formas verbales pertenecientes también al dominio de lo personal; 4 . consecuencia de la forma interior de la lengua española que lleva a la distinción entre referentes personales y no personales y cuyo reflejo puede hallarse en otros hechos sintácticos, como la presencia de la preposición $a$ ante complemento directo de persona 4 .

Junto a la investigación sobre los orígenes de tales fenómenos se han realizado también contribuciones muy meritorias sobre su evolución en las diferentes etapas de la lengua española, y aunque los datos procedan siempre de textos escritos - no siempre fuentes de primera mano para conocer los verdaderos estadios de lengua pretéritos- lo cierto es que hoy es posible trazar un panorama, siquiera aproximado, de los principales hitos. En este sentido, el estudio de la gramática normativa que surge con la Academia a finales del siglo XVIII ha contribuido notablemente al esclarecimiento de muchos puntos en relación con el uso de estos pronombres. Es bien sabido, por ejemplo, que el laísmo encontró en la prohibición académica de 1796 un freno importante para su extensión social, truncando así una evolución mucho más activa en siglos anteriores, como demuestran los textos de algunos autores barrocos (Marcos, 1978: 207-10). El leísmo, por su parte, ha sido objeto también de una notable metamorfosis normativista, desde su aceptación generalizada para la expresión de referentes masculinos (de persona y cosa) en la primera Gramática académica ${ }^{5}$ hasta las versiones más recientes de ésta en las que se vuelve la mirada al sistema etimo-

3 Esta circunstancia ha hecho que MARCos MarfN (1978: 13) distinga en su trabajo entre usos anómalos -aquellos en los que se vulnera el sistema etimologico-casual heredado del latín por el español- y usos aparentemente anómalos —en los que el leismo ya aparece registrado en los enunciados del latín tardío-. Por lo tanto, en estos últimos casos el leísmo serfa perfectamente etimológico.

4 Algunos autores como Monge (1983: 443) y Marcos (1978: 18) han recordado tambien la influencia de las construcciones en las que se emplea le junto con el llamado se impersonal, desarrollo postmedieval de la pasiva refleja v. gr. se recibe al embajador / se le recibe.

5 Bien es cierto que sólo para el singular, ya que se proponía los como único pronombre de O.D plural. 
lógico originario y en las que, como única concesión, se tolera el leísmo de persona ${ }^{6}$.

A la vista de este notable interés por el conocimiento de los orígenes y de la evolución de estos fenómenos, desconcierta un tanto el panorama mucho menos esperanzador que arrojan los estudios sobre el español moderno, especialmente si tenemos en cuenta que hoy contamos con muchos más medios metodológicos y teóricos con los que afrontar el problema. Desde un punto de vista empírico, sorprende, por ejemplo, que las enormes posibilidades que en la actualidad ofrecen los métodos de recolección del habla real no se hayan reflejado en una mayor profusión de trabajos en los que se analicen los datos geográficos, sociales y lingüísticos que hoy presentan fenómenos como el leísmo o el laísmo en el español actual. Hasta hace bien poco, por ejemplo, los únicos datos que poseíamos acerca de su distribución geolingüística procedían de los escasos materiales aportados por diversos atlas linguísticos, así como por referencias dispersas en monografías dialectales (Llorente, 1980: 22-23), noticias muy escasas, y en todo caso, referidas casi exclusivamente al mundo rural 7 .

Prácticamente hasta comienzos de la última década, las únicas referencias que se añaden a las esbozadas en el párrafo anterior proceden de diversos gramáticos cuya aproximación a nuestros fenómenos tienen en algunos casos notable interés, pero que, o bien proceden de datos extraídos -como siempre- de la lengua escrita o bien adolecen de un excesivo impresionismo difícilmente comprobable desde un punto de vista empírico. Desde los ya un tanto lejanos apuntes de Cuervo (1895), que vio en el habla de Madrid el centro irradiador

6 Se trata, sin embargo, de una tolerancia relativa, ya que desde una punto de vista normativo se aconseja el empleo casual de los pronombres. Así lo ha hecho, entre otros, LLORENTE (1980: 24), quien señala: * (el leísmo de complemento directo masculino de persona) que como es bien sabido, está admitido o tolerado por la Real Academia Española, pero no resulta verdaderamente correcto ni verdaderamente elegantew [vid. también GnI (1958: 209-10)].

Otros hitos importantes en dicha evolucion, apenas esbozada en las líneas de arriba, son las que representan figuras como SALVA (1830) y BELL (1847/1964). Siguiendo una tradición normativa que arranca del maestro CORREAs, proponen la aplicación del criterio de la animación para el uso de los pronombres le/lo en la referencia del O.D (Le para seres animados y lo para seres inanimados). Asimismo, y frente al criterio académico, toleran el uso de les para el plural e incluso algunos casos de laísmo, siempre que con ello se pretenda evitar una ambigüedad.

7 La conciencia de tales limitaciones aparece también en las siguientes palabras de FERNANDEZ Ramfrez (1964: 279), una de las figuras más autorizadas en el estudio de estos fenómenos: «Fuera de algunas áreas más o menos homogéneas, poco sabemos hoy de la distribución geografica de unas u otras formas. Ignoramos si existen límites claros, por ejemplo, entre un leísmo riguroso y un leismo atenuado, dentro de la Península. Todo hace pensar que las diferencias entre las hablas individuales son en este punto innumerables y que más que de áreas de dialectos cabria hablar aqur de idiolectos». 
principal del leísmo en la Península, no han faltado entre nuestros lingüistas algunas aportaciones sobre el tema. Gili Gaya (1958: 210-11), por ejemplo, indicaba a propósito de el leísmo y el laísmo que «es el uso madrileño espontáneo en todas las clases sociales, a no ser entre personas cuya instrucción gramatical, o la procedencia de otras regiones, lo corrija más o menos». En el mismo sentido que Cuervo, advertía el gramático español que «la influencia de la capital irradia su laísmo hacia otras provincias del Centro y del Norte, llegando a vencer a menudo la resistencia del lenguaje literario. El vulgo madrileño va todavía más allá: el lo sustituye con frecuencia a le como dativo: lo pegaron una bofetada. Sin embargo, este loísmo se siente en todas partes como extremadamente plebeyo, y no ha logrado salir del habla achulapada». Por su parte, autores como Fernández Ramírez (1951) o Marcos Marín (1978) han deducido a partir de sus innumerables y valiosos recuentos sobre la lengua literaria de este último siglo que las variaciones en el uso del sistema pronominal pueden obedecer quizá más a diferencias culturales o idiolectales entre los autores que a su origen geográfico. En palabras del último de los investigadores mencionados (Marcos Marín, 1978: 260): «en la lengua escrita parecen primar criterios socioculturales o socioliterarios». Asimismo, este autor ha llamado la atención sobre la influencia actual de los medios de comunicación en la lengua hablada actual (vid. también Llorente, 1980: 26) ${ }^{8}$.

\section{ESTUDIOS RECIENTES SOBRE LEISMO, LAISMO Y LOISMO}

El estado de cosas sobre la investigación del leísmo, laísmo y loísmo descrito en los párrafos anteriores era resumido por Llorente (1980: 22) de esta forma tan pesimista: «las características y la difusión geográfica de estas tres des-

8 Como no figura dentro de nuestros objetivos el aportar un estado de la cuestion sobre el tema, dejamos de lado otras referencias sobre el uso de los pronombres de tercera persona en diversos corpora literarios. Valga con mencionar, aparte de los ya reseffados, los trabajos de SCHMIDELY (1972) sobre una novela de JUAN GoYTISOLO, La resaca, y TRINIDAD (1969) sobre la lengua de Ar-
niches.

Por otro lado, y ya que nuestra intención es contribuir al conocimiento de la distribución geografica y social de estos fenómenos en una comunidad de habla peninsular, obviamos el comentario de la bibliografía sobre el español de América. Un buen resumen de algunos trabajos publicados hasta la fecha sobre esta área del español es el que ofrecen Qun.Is y sus colaboradores (1985). En este trabajo se recuerda la menor extensión de dichos fenómenos en el español americano, asi como algunas de sus especificidades en diversas áreas geográficas (véase, por ejemplo, el trabajo 
viaciones de la norma son muy mal conocidas. No ha habido una investigación sistemática de estos fenómenos sobre el propio terreno, por lo que realmente no sabemos, ni siquiera aproximadamente, lo que ocurre en la lengua hablada de las distintas regiones del dominio del español. Por otra parte, lo que hasta ahora se ha dicho de estas incorrecciones se basa en los datos suministrados por los textos, «datos que no son de fiar, pues más que el habla o el idiolecto de los distintos autores o el habla de las distintas regiones (cuando se trata, por ejemplo, de colecciones de cuentos populares), lo que reflejan estos datos es el habla o el idiolecto de los tipógrafos, linotipistas y correctores de pruebas».

Como han advertido Quilis y sus colaboradores (1985: 28), el artículo de Llorente (1980) recogía prácticamente todo lo que en ese momento era posible conocer sobre la difusión geográfica de estos fenómenos, lo cual no era ciertamente mucho. En cualquier caso, este autor tuvo el mérito no sólo de reunir los datos dispersos en diversos atlas lingüísticos y trabajos de geografía dialectal publicados, sino también de realizar algunas calas en algunas modalidades específicas, especialmente del leísmo, poco atendidas hasta ese momento ${ }^{9}$. En otro orden de cosas, Llorente realizaba algunas consideraciones sociolingüísti-

de GRANDA (1981) sobre el singular leismo paraguayo, fenómeno que el lingüista español atribuye a una causación múltiple (interferencia del guaraní, base dialectal peninsular en el momento de la colonización, simplificaciones lingúrsticas propias de las áreas periféricas...).

9 LLORENTE (1980: 24-5) apunta que el fenómeno más extendido geográfica y socialmente es el léismo de persona masculina, que se da en gran parte de la Meseta Norte y de la Meseta Sur, en la mayor parte de Extremadura, en la parte más occidental de la Rioja, en el norte de Burgos (Valle del Ebro), Santander, Asturias, en el castellano de Galicia, País Vasco y parte de Navarra, así como en algunos pueblos aragoneses limitrofes con Castilla. Con relación al leísmo referido a seres inanimados, señala este autor que se produce en un área geografica más limitada que el anterior (no aparece, por ejemplo, en las provincias occidentales de León, Zamora y Salamanca; sin embargo, es habitual en toda Castilla la Vieja, la Rioja Alta, mitad occidental de la Rioja Baja, en la franja más occidental de Aragón, en ciertas provincias de Castilla la Nueva como Guadalajara, Madrid y gran parte de Toledo y de Cuenca.

Por lo que se refiere al leismo de complemento directo «neutro» (no se le dije), indica Llorente que se da «de forma anárquica y vacilante en un área que no puedo precisar, pero que gravita sobre el Sistema Ibérico, en sus dos vertientes (castellana y aragonesa). Por último el lefsmo de complemento directo femenino [le vi (a Maria)] es un fenómeno caracteristico del castellano del País Vasco y de su entormo, incluyendo gran parte de Navarra, el extremo occidental de La Rioja, la parte oriental de Santander y «quizá las comarcas burgalesas del Valle del Ebro». Respecto al leísmo, advierte que su área de extensión es similar a la del lé́smo de cosa, aunque algo más pequeña.

Por último, y en relación con el loísmo, Llorente apunta que, cargado de connotaciones peyorativas, todavía «me atrevo a decir que el loísmo tiene bastante vitalidad, dentro de un área geográfica que englobaria las capitales - y parte de sus respectivas provincias- de Madrid, Segovia, Valladolid, Avila, también parte de las provincias de Toledo y Palencia, y la orla oriental de las provincias de Zamora y Salamanca. Y parece ser que el loísmo tiene también cierta vitalidad en Asturias, sobre todo en bable central y bable oriental». 
cas de interés, como la reflexión acerca del papel desempeñado por los medios de comunicación centralistas en la difusión del leísmo y el laísmo, difusión que, a su juicio, ha aumentado considerablemente respecto a épocas relativamente recientes tanto en el eje diatópico como en el eje diastrático ${ }^{10}$. Por último, cerraba su breve descripción geolectal de tales fenómenos desde una óptica normativista que reproducimos aquí por el interés que, como veremos, tiene para nuestro propio objeto de estudio: «Confiemos en que los andaluces, murcianos, aragoneses, hispanoamericanos y los hispanohablantes de Cataluña, Levante y Baleares resistan denodadamente, se muestren inmunes a la infección y sigan, en este aspecto concreto, hablando y escribiendo con corrección y elegancia nuestra lengua, como lo han hecho hasta ahora» (p. 27).

Probablemente haya sido la lingüista americana F. Klein $(1979 ; 1981)$ una de las primeras investigadoras en reclamar la importancia de un estudio sincrónico sobre el empleo de los pronombres átonos de tercera persona. Y ello desde una doble optica: en primer lugar averiguando las normas («en el sentido de Coseriu») que caracterizan la lengua hablada en distintas regiones geográficas y, en segundo lugar, determinando así los principios lingüísticos («el sistema») y la dinámica sociolingüística que dichas normas manifiestan (Klein, 1981: 285). La novedad de la propuesta de Klein no consiste sólo en alentar a la realización de tales análisis empíricos sobre diferentes áreas del español, sino, principalmente, en el cambio de perspectiva teórico y metodológico para la realización de tales estudios. En efecto, se confía a la disciplina sociolingüística la tarea de precisar el alcance geográfico y social de estos fenómenos, sustituyendo los métodos de la geografía dialectal por los más avanzados de la sociolingüística, para establecer así una radiografía mucho más precisa en la que se aborden problemas hasta ahora desatendidos, como la distribución o evaluación social de dichos rasgos lingüísticos o el mismo cambio lingüístico. No en vano - señala la misma Klein- «una investigación semejante podría arrojar incluso nueva luz sobre el aspecto diacrónico de la cuestión, contribuyendo así a aclarar algunos puntos que acaban de explicarse del todo por vías tradicionales, según indicaremos más adelante» (p. 285).

El propio estudio de esta autora sobre el leísmo, el laísmo y el loísmo en diversas provincias de Castilla la Vieja ha aportado algunos datos sociolingüís-

10 « La causa de la propagación de estas desviaciones será la tendencia inevitable a imitar la manera de hablar de los habitantes del centro de España, sobre todo de los madrileños, ungidos por el prestigio de la capitalidad, como otros han imaginado? No lo sé, no sabria dar respuesta a semejantes preguntas, pero es un hecho la propagación de estas incorrecciones en los dos sentidos de que antes hablaba, en el eje diatópico y en el eje diastrático, una propagación acelerada y a ojos vistas» (p. 26). 
ticos de interés. Así, por ejemplo, las importantes diferencias observables en la difusión social de tales fenómenos entre provincias occidentales como Valladolid y otras más orientales como Soria o Logroño: mientras en la primera los índices de leísmo - de persona y cosa- y laísmo son muy elevados, en las dos últimas el sistema vernáculo es mayoritariamente casual, con la excepción de un considerable grado de leísmo de persona, si bien no tan elevado como en Valladolid. Por otro lado, se aprecian también diferencias en los patrones de evaluación subjetiva de tales rasgos, siendo considerado el leísmo de persona como la norma de prestigio «castellanizante» en la mayoría de los territorios analizados -aunque con discrepancias de interés ${ }^{11}$, lo que sirve a esta investigadora como medida del «regionalismo implícito» o «solidaridad regional» que enfrenta estas comunidades de habla castellanas a otras áreas sociolingüísticas del español.

El reto de unos objetivos y una metodología característicamente sociolinguiísticos para el análisis de estas variables ha sido asumido, afortunadamente, por otros investigadores, que en la última década han aportado valiosas contribuciones a nuestro objeto de estudio ${ }^{12}$. En este sentido destaca, por ejemplo, la investigación sobre el leísmo y el laísmo de persona en la ciudad de Burgos realizado por Martínez Martín (1984). A partir de un trabajo de campo riguro-

${ }^{11}$ Así, son de nuevo las provincias occidentales las que muestran una mayor unanimidad en este tema, mientras que sólo algunos grupos sociales, como las clases medias -n Soria- o las mujeres -en Logroño-, sobresalen en la consideración prestigiosa de este fenómeno. Mayores diferencias se aprecian en la valoración del larsmo.

12 Antes incluso de la aparición de los trabajos de Klein, otros autores participaron también del interés por investigar los fenómenos del lésmo, laísmo y loísmo como variables sociolinguilsticas. Asf, en un trabajo pionero de la disciplina en nuestro país centrado en el análisis de la conducta lingúfstica de la Sevilla urbana, LAMiQuz (1976: 361) vio en la ausencia absoluta del larsmo, asf como en la escasisima presencia de leísmo de persona, uno de los rasgos singulares de la «sevillanía linglística, meta de consecución que enfrenta al grupo sociolingúístico sevillano no solo a las comunidades castellanas, sino incluso a otras andaluzas.

En un sentido algo diferentes habria que mencionar otros trabajos desarrollados en diversas áreas geograficas, como el de LoREnzo Ramos (1981) sobre el español de Canarias. En lugar de una investigación propiamente sociolinguística, habrfa que hablar en este caso de andisis con intereses vinculados tradicionalmente a esa disciplina cientifica o incluso a la etnografia del habla, como las observaciones realizadas en tomo a la distribución de los clíticos en diferentes contextos de situación (v. gr. la cortesía, la oposición poder/solidaridad en la conversación, etc.).

Como diferente es tambien el trabajo de Garcta GonzÁlez (1978), a quien debemos uno de los primeros estudios sistemáticos sobre estos fenómenos en el español actual desde un punto de vista sincrónico y a partir de los datos del habla real. Sin embargo, los objetivos de este interesantrsimo trabajo van encaminados sobre todo al análisis de los diferentes «sistemas* pronominales que se distribuyen por las distintas hablas santanderinas, trabajo de geografia dialectal estructuralista al que, no obstante, se añaden en ocasiones valiosas apreciaciones de caracter social. 
so, este autor concluye que en dicha ciudad castellana leísmo y laísmo tienen una enorme extensión social, pero se caracterizan como modelos de variables sociolingüísticas diferentes. Así, mientras el leísmo puede ser considerado como un indicador, dada la ausencia de estratificación social y estilística en su difusión por la sociedad, el laísmo encaja mejor en la concepción laboviana (Labov, 1972/83:) de los marcadores sociolingüísticos. En efecto, en su estudio se comprueba que, pese al empleo generalizado de la para la expresión del O.I. femenino de persona entre todas los grupos sociales, hay diferencias estadísticas relevantes entre los niveles de formalidad discursiva: el nivel de laísmo desciende conforme el estilo se hace más formal, lo que se acusa todavía más entre los estratos socioculturales elevados. Con todo, el laísmo no aparece ni mucho menos estigmatizado en el habla urbana de Burgos ya que los individuos pertenecientes a tales capas sociales hacen un uso abundante de él en los estilos de habla más coloquiales e informales. Por último, el estudio de Martínez se completa con un análisis de las actitudes lingüísticas hacia dichas variables, análisis en el que destaca la aceptación del leísmo como un castellanismo generalizado, así como un cierto grado de inseguridad linguística respecto al laísmo, de cuyo grado de aceptación se duda mucho más.

Probablemente, el estudio más completo desarrollado en nuestro país hasta el momento, especialmente por el volumen de datos analizados, ha sido el que Quilis y un grupo de colaboradores (Quilis y otros, 1985) han realizado sobre el empleo de los pronombres átonos en la ciudad de Madrid, trabajo que los autores sitúan en el marco de las investigaciones que sobre la norma culta de la principales ciudades del mundo hispánico se vienen desarrollado, con desigual fortuna, desde hace un par de décadas. A la importancia intrínseca de los datos aportados en este trabajo se une la consideración acerca de la influencia social que esta norma culta madrileña puede imponer a otros territorios españoles, observación que, como vimos, ya realizaran autores como Cuervo, y que en los últimos tiempos tiende a convertirse en una importante hipótesis de trabajo, especialmente por la trascendencia social de los medios de comunicación - sobre todo la televisión-, enclavados mayoritariamente, como se sabe, en la capital de España. Como conclusiones generales más relevantes del trabajo de Quilis y sus colaboradores (1985: 207-11) se desprende que los madrileños pertenecientes a los niveles socioculturales y económicos más altos no pueden ser caracterizados por el empleo de un sistema referencial acabado y opuesto al sistema etimológico-causal, presuntamente común en otras regiones españolas no castellanas. Más bien al contrario, parece que la presión normativa es en este estamento de la sociedad bastante importante, lo que se aprecia en una tendencia al uso etimologico, con frecuencias relativas bajas de leísmo de cosa y ausencia total de loísmo, aunque con la importante 
variedad del leísmo de persona, ciertamente extendido. La aspiración latente al empleo etimológico de los pronombres se comprueba asimismo en el escaso nivel de laísmo observado. No obstante, lo autores indican que esta tendencia general a evitar el laísmo contrasta con la frecuencia elevada de la como O.I. con ciertos verbos de empleo muy habitual en el habla (decir, dar, gustar, cantar, quitar...), lo que, sin duda, produce esa impresión de laísmo generalizado que, en su opinión, está muy lejos de ser cierta ${ }^{13}$. Para este grupo de investigadores, finalmente, las desviaciones con respecto al modelo etimológico, considerado en este trabajo como tradicional entre los madrileños cultos, pueden ser la antesala de modificaciones importantes: «posiblemente estemos asistiendo a la lucha entre el modelo y las variantes minoritarias, previa, sin duda, a todo cambio lingüístico» (p. 210 $)^{14}$.

Con pretensiones más modestas, como los mismos autores reconocen, pero sin limitar el objeto de estudio a la norma culta, un grupo de investigadores encabezados por Moreno Fernández se propuso pocos años después - Moreno Fernández y otros (1988) - el estudio del uso de los pronombres átonos de 3." persona en 23 localidades de la provincia de Madrid. A partir de una muestra de 184 informantes — cantidad poco habitual en los estudios sociolingüísticos- distribuidos a través de las variables sociológicas de sexo y edad, este grupo de dialectólogos y sociolingüistas concluyó que la extensión social del leísmo y el laísmo en los municipios de la provincia de Madrid era grande, aunque quizá no en la medida esperada. Por otro lado, el estudio de la covariación con las variables sociológicas empleadas no arrojó ningún resultado significativo, por lo que no pudo demostrarse la existencia de modelos de actuación

13 Como en este mismo trabajo se indica, la tendencia al mantenimiento de la eficacia funcional del sistema etimológico, apreciada, por ejemplo, en los bajos niveles generales de lafsmo se ve reforzada en el caso de algunos hablantes por fenómenos de hipercorrección, como el uso de le para la expresión del O.D. femenino.

14 Otras conclusiones interesantes que se desprenden de este trabajo hablan de la nula significación de algunas variables introducidas en el trabajo de campo para el análisis de la variación. Asf, por ejemplo, ni el morfema de número, ni el tipo de encuesta, y por tanto de formalidad, se revelan estadísticamente significativos en la distribución de los pronombres. Por lo que se refiere a otra clase de variables, esta vez sociales, como el sexo o la edad, hay que decir que no se aprecian diferencias generales importantes. Parece, por ejemplo, que las mujeres son algo menos leístas que los hombres, pero el test de probabilidad estadística sitúa estas diferencias muy cerca del umbral de significación. Diferencias que se hacen nulas, por otro lado, en el caso del lafsmo. Por edades, y aunque más como indicio que como prueba, se observa una curiosa contradicción entre el estrato generacional más joven y los demás: aquellos parecen, por un lado, más laístas que los demás, a la vez que manifiestan una mayor inclinación por el modelo etimológico en el caso del lefsmo. 
sociolingüística diferente ni entre los dos sexos ni entre los distintos estratos generacionales $^{15}$.

\section{NUESTRO OBJETO DE ESTUDIO}

La aparición en los últimos quince años de diversos estudios que abordan no sólo la perspectiva geolectal del análisis, sino también otros aspectos sociolinguísticos, ha contribuido a un conocimiento mejor de las realizaciones y la distribución social de los fenómenos que estamos abordando, de manera que la situación actual no podría ser descrita con la misma dosis de pesimismo que mostraba Llorente (1980) en el artículo anteriormente reseñado.

Ahora bien, una primera reflexión sobre el trabajo hasta ahora realizado permite advertir que las investigaciones empíricas en nuestro país se circunscriben a un corpus geográfico muy concreto y limitado como el que corresponde a las comunidades de habla castellanas. El hecho de que la linguiística histórica y la geografía dialectal hayan caracterizado tradicionalmente este fenómeno como típicamente castellano ha debido influir, sin duda, en el interés por el análisis casi exclusivo de esta variedad lectal.

Lo cierto es que a estas alturas las noticias sobre el uso de los pronombres átonos de 3.' persona en otras regiones españolas sigue adoleciendo de los mismos problemas que apuntábamos anteriormente. Los datos extraídos de algunos atlas lingüísticos y monografías dialectales presentan un panorama muy poco preciso sobre la cuestion (Llorente, 1980: 22-26), adquiriendo en este sentido especial relevancia las escasísimas noticias sobre el español hablado en la regiones bilingües españolas. Así ocurre, por ejemplo, con los conocimientos que hoy tenemos sobre el uso de le, la, lo en comunidades levantinas como Cataluña o el País Valenciano, donde la falta de investigaciones concretas sobre el tema no ha impedido extender la impresión de que en ellas se da un uso ortodoxo de

15 En el caso de la diferenciación generacional, y a pesar de que los análisis de fiabilidad estadistica a partir de la muestra utilizada no arrojan diferencias significativas, se aprecia, no obstante, una gradación ascendente en la presencia del leísmo conforme aumenta la edad de los informantes. A partir de estos datos, los autores de la investigación postulan la posible influencia de la normativa en los estratos mas jóvenes por el mayor contacto con instituciones normativistas como la escuela. Recuerdese a este proposito un resultado semejante extrardo tras la investigación de Quilus y oTros (1985) para el lérsmo - aunque no para el larsmo, donde ocurre paradojicamente al revés, lo que viene a sembrar dudas respecto a la verosimilitud de tal hipótesis-. 
los pronombres, acorde con el sistema etimológico-casual. El mismo Llorente (1980: 26), alertando del peligro que para la norma prescriptiva del español supone la extensión de fenómenos como el leísmo, el laísmo o incluso el loísmo, pone a catalanes, baleares y valencianos - junto a andaluces o hispanoamericanos- como ejemplo de resistencia frente a la invasión castellanizante ${ }^{16}$.

Así las cosas, el principal objetivo de nuestro trabajo será, precisamente, la confirmación o no de tales hipótesis a través de una investigación empírica que toma como presupuestos teóricos y metodológicos los habituales en la ciencia lingüística.

\section{HIPOTESIS Y METODOLOGIA}

Para ello hemos elegido una muestra de población de un área bilingüe del País Valenciano. Se trata de la comarca del Camp de Turia, región que se extiende hacia el interior de la provincia de Valencia y en la que se produce una situación de bilingüismo social (Rojo, 1981) con alternancia funcional fundamentalmente diglósica - como en casi todas las comarcas valenciano-hablantes- entre el catalán y el castellano.

El trabajo de campo parte de una muestra de 88 jóvenes procedentes de distintas poblaciones de la comarca valenciana, especialmente de La Eliana, municipio de cuyo instituto de bachillerato son alumnos la mayoría. Los datos lingüísticos de la investigación han sido obtenidos tras la aplicación de tres procedimientos diferentes, siguiendo así una tradición metodológica que persigue el análisis de la covariación entre el habla y distintos grados de formalidad discursiva (Labov, 1972/83: cap. 3):

1. Grabaciones del habla de los informantes a partir de conversaciones dirigidas y semidirigidas sobre las expectativas académicas y profesionales de éstos ${ }^{17}$.

16 *Confiemos en que los andaluces, murcianos, aragoneses, hispanoamericanos, y los hispanohablantes de Cataluña, Levante y Baleares resistan denodadamente, se muestren inmunes a la infección y sigan, en este aspecto concreto, hablando y escribiendo con corrección y elegancia nuestra lengua, como lo han hecho hasta ahora*.

17 Estas grabaciones proceden en buena parte del material acumulado por el Servicio de Orientación Profesional del Instituto de La Eliana durante el curso 1990-91. El resto fueron realizadas por quien esto escribe en conversaciones privadas o en grupo con estos alumnos, material al que hay que añadir, finalmente, las observaciones concretas que sobre el habla de estos jovenes hemos realizado en los últimos affos. 
2. La realización de un test de complementación (Silva-Corvalán, 1989: 37). Partimos de la hipótesis de que el contraste entre los datos anteriores y los obtenidos con esta técnica indirecta nos dará la medida de hasta qué punto la variación estilística influye en la realización de las variables linguiísticas analizadas.

3. La respuesta de los hablantes a un test de aceptabilidad con el que pretendemos medir el grado de corrección que los hablantes otorgan a cada una de las variantes objeto de estudio. Por otro lado, el análisis comparativo entre los datos obtenidos con esta clase de técnicas evaluativas y el uso real, suele ser utilizado a menudo como muestra de la inseguridad lingüística de los hablantes (López Morales, 1989: 222), dato importante para un conocimiento más completo de los modelos sociolingüísticos que actúan en la comunidad estudiada, así como para la predicción de posibles cambios lingüísticos.

Como variables linguiísticas objeto de análisis proponemos las siguientes:

a) Uso de los pronombres lo/le para la expresión del objeto directo masculino de persona. Para facilitar el tratamiento informático y estadístico de la información relativa a esta variable proponemos el nombre de leísmo/persona a partir de este momento. Partimos, en consecuencia de la consideración apriorística de ésta como una variable sintáctica apta para la investigación sociolingüística (Sankoff, 1988/92: 192), cuyas variantes (los pronombres le/lo) nos darán la medida, llegado el caso, de si existe una covariación significativa con factores sociales o contextuales.

b) Uso de los pronombres lo/le para la expresión del objeto directo masculino de objeto no viviente. Damos el nombre de leísmo/cosa a esta segunda variable.

c) Uso de los pronombres le/la para la expresión del objeto indirecto de persona femenina. Llamaremos laísmo a esta última variable lingüística.

El análisis de la covariación entre tales variables y otros factores no linguiísticos se plantea en la presente investigación a partir de dos clases de variables no estructurales: por un lado, la que representan los diferentes registros o estilos en que aparecen los fenómenos lingüísticos estudiados y que ya han sido reseñados en párrafos anteriores. Por otro, una serie de factores sociales cuya potencial influencia en la variación lingüística ha sido demostrada en numerosas ocasiones, y que en nuestro caso son:

1. Sexo: La muestra aparece dividida en dos grupos: 41 hombres y 47 mujeres. 
2. Origen: Se pretende medir el influjo que la procedencia de los informantes puede tener en la realización de las variables linguiísticas. Como se advirtió en otro momento, el área geográfica analizada presenta un cantidad nada despreciable de inmigrantes originarios de otras regiones españolas, especialmente del centro de España, principal foco como ya hemos visto, para la difusión de estos fenómenos en el contexto peninsular. Partimos, en consecuencia, de la hipótesis de que es posible hallar un comportamiento lingüístico diferenciado entre el grupo de hablantes nacido en Valencia (la mayoría: 70) y aquellos otros procedentes de otras regiones peninsulares [Fuera (18)].

3. Competencia lingüística (bilingüismo): en línea con otras investigaciones que hemos llevado a cabo anteriormente sobre estas comunidades bilingües (Blas, 1992; 1993), deseamos averiguar si la competencia monolingüe (castellano-hablante exclusivo) o bilingüe de los informantes tiene alguna relevancia cuantitativa en la realización y distribución social de los pronombres átonos. El hecho de que los hablantes bilingües completen su gramática con la de otra lengua, como en este caso la catalana ${ }^{18}$, admite, al menos como hipótesis de trabajo, que dicho rasgo sea tenido en consideración como posible freno a las desviaciones del sistema etimológico en español. La distribución de la población encuestada a partir de este factor queda dividida en los dos grupos siguientes: Monolingües (38); Bilingües (50).

18 El catalán sigue un sistema etimológico-casual en el que se distinguen también formas de O.D. y formas de O.I. Por lo que se refiere a las primeras, BADlA (1962/85: 173-5) señala que son cuatro pronombres, alguno de los cuales puede revestir distintas formas, dependiendo de su situación en el conjunto de la oración: el $\left(y l o, l^{\prime} l, l^{\prime}\right)$ - para masculino singular-, la $\left(y l^{\prime}\right)$-femenino singular-, els (y los, 'ls) -masculino plural-y les - femenino plural- Ej.: tinc un llibre: mira'l, ara l'obro, el tanco, vaig a desar-lo («tengo un libro: mfralo, ahora lo abro, lo cierro, voy a guardarlo", ejemplo de BADfA (1962/85: 174).

Para la función de objeto indirecto, la lengua catalana dispone de dos formas: $l i$ (singular e indistintamente para ambos géneros) y els (y los, $1 s$ ) (para el plural, y también indistintamente, tanto para masculino como para femenino). Ej.: crida el teu germa $i$ dona-li el diari («llama a tu hermano y dale el diario»; ejemplo de Badía).

El lingliista catalán, consciente de la vitalidad del leŕsmo y del laísmo en el habla de algunas áreas del espafiol, indica que entre las principales discrepancias en el uso pronominal átono de tercera persona en catalán y español, sobresalen las diferentes equivalencias entre las formas de ambas lenguas; así, por ejemplo, el pronombre «le» tiene en castellano valor de complemento directo y de complemento indirecto; en el primer caso se traduce por $e l$, en el segundo por li: “ ¿conoces a mi hermano?, no le conozco* / coneix el meu germa? no el conec. «Hay carta de mi hijo, le escribiré mañana / hi ha carta del meu fill, li escriuré demd. Y lo mismo con la forma del plural (les) y con los pronombres «la $y$ *las» (pp. 175-6). 
Por último, y aunque su análisis no pueda ser directamente evaluado en esta investigación, partimos de la hipótesis de una influencia positiva de los medios de comunicación -especialmente la televisión- en la extensión social de los fenómenos aquí estudiados. Si en nuestros días la evolución de la norma -en el sentido coseriano- guarda cada vez una mayor relación con la huella ejercida por estos medios audiovisuales y escritos, y si en nuestro país tales medios en lengua castellana proceden en su mayor parte del centro de España, es previsible encontrar también dicha influencia en nuestra comunidad objeto de estudio.

Para concluir este capítulo dedicado a la descripción de los aspectos metodológicos de la investigación, digamos que la información será cuantificada por medio de recuentos frecuenciales absolutos y relativos (porcentajes de aparición de cada una de las variantes). Las diferencias entre las frecuencias obtenidas por los distintos grupos serán objeto de un análisis de varianza para averiguar si, dadas las dimensiones de la muestra estudiada, éstas resultan significativas o si, por el contrario, no es posible descartar el azar en su configuración (Moreno Fernández, 1990: 138) ${ }^{19}$. Para facilitar, por último, la comprensión de los datos que se van aportando, recurrimos a algunas representaciones gráficas como tablas estadísticas, gráficos de líneas, de barras, etcétera.

\section{REALIZACIONES Y DISTRIBUCIÓN DE LOS PRONOMBRES LO/LE OBJETO DIRECTO DE PERSONA MASCULINO (LEISMO/PERSONA)}

En la Tabla de valores 1 (Anejo 1) pueden consultarse las frecuencias absolutas de aparición, así como la traducción en los porcentajes correspondientes de las dos variantes en que aparece distribuida la variable que hemos denominado leísmo/persona.

Como puede observarse allí, la frecuencia de le para la expresión del O.D. de persona masculina es casi cinco veces superior a la de $l o$, dato que parece invalidar en nuestro caso la hipotesis tradicional acerca del uso mayoritariamente etimológico de estos pronombres en las comunidades levantinas. Las

19 Como criterios de probabilidad principales utilizamos los valores aportados por los estadísticos $F$ y $t$ - student. Hemos utilizado para ello el programa de estadística para ordenador Superanova. 
abultadas diferencias porcentuales son avaladas, además, por los análisis estadísticos de significación que conceden una probabilidad del 91 por 1.000 de que no sean debidas al azar, sino que respondan a discrepancias relevantes en el uso de la variable lingüística en el seno de la población estudiada (Anejo 2).

Para analizar la distribución de estos resultados globales entre los distintos grupos sociológicos en que estructuramos la muestra y comprobar si existen diferencias sociolingüísticamente relevantes entre ellos, ofrecemos el siguiente cuadro de barras en el que aparecen agrupados de dos en dos los datos correspondientes a cada una de las variables no estructurales: sexo, origen y competencia lingüística (monolingüe/bilingüe).

CuAdro 1

Correlación variable «leismo/persona/variables sociales

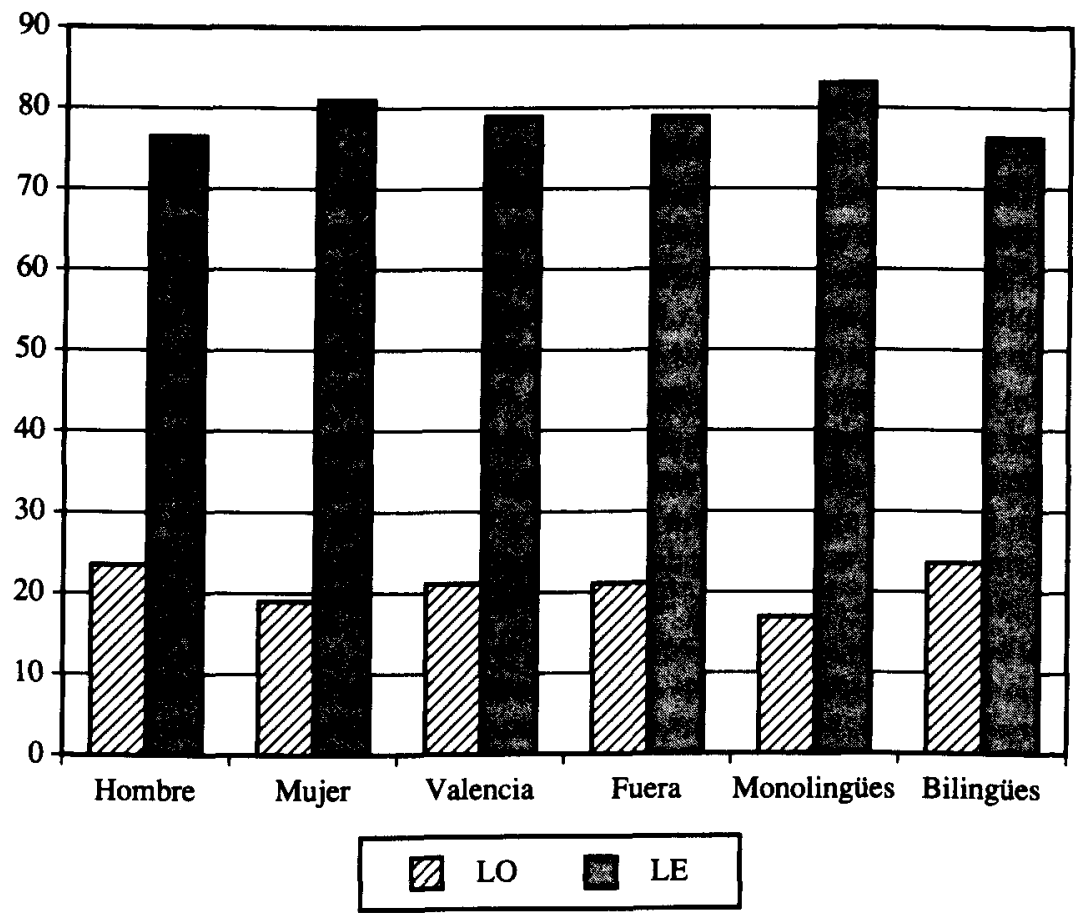


A la vista de estos datos, no parece posible concluir que existan diferencias sociolingüísticas significativas en el uso de estos pronombres en el seno de la comunidad. Un análisis de varianza a partir de las cifras obtenidas por los diferentes grupos arroja unos índices de significación muy bajos, que se corresponden con una grado de confianza inferior al 12\%, lo cual invalida cualquier posibilidad de rechazar la hipótesis nula y por consiguiente, de confirmar la relevancia de las diferencias grupales.

Si pasamos a un análisis detallado de la incidencia en la variación de cada una de las variables sociológicas, comprobamos como dato más significativo la absoluta homogeneidad en el comportamiento hacia esta variable lingüística por parte de los dos grupos de origen, es decir, los nacidos en Valencia y los originarios de otras regiones españolas - mayoritariamente, recuérdese, del centro de España- A pesar de las importantes diferencias muestrales entre ambos grupos - derivadas, lógicamente, de la menor presencia en la muestra de los inmigrantes - tanto los resultados porcentuales - 78'9\% de uso de le para ambos grupos- como los estadísticos de significación $-F: 9.590 \mathrm{E}$ y $t: 003$ con un valor $P$. del 997 - dan cuenta de una nula variabilidad condicionada por la procedencia de los hablantes. Estos datos, unidos al elevado índice de empleo de le para la expresión del O.D. masculino de persona, ponen de relieve que, al menos entre la población juvenil de esta comunidad valenciana, la supuesta resistencia a los usos no etimológicos de esta variable no se ve confirmada en absoluto por la realidad.

Por lo que se refiere al sexo, las diferencias son aquí algo mayores, con una aparente mayor inclinación de la mujer hacia el uso de un sistema referencial. Sin embargo, sería extraordinariamente arriesgado vincular estos datos a las conclusiones que sobre la diferenciación sexual se han realizado en la investigación sociolingüística de las últimas décadas (Smith, 1985), en el sentido de que las mujeres suelen adoptar en un mayor grado que los hombres las variantes más influyentes de la sociedad, ya que las tales diferencias se ven estadísticamente invalidadas en nuestro caso por los test de probabilidad. En efecto, un nivel de significación del 442 arrojado por el análisis de varianza confirma que, al menos a partir de la muestra por nosotros analizada, no puede afirmarse que las diferencias halladas entre hombres y mujeres en el uso de la variable leísmo/persona no sean debidas al azar.

Diferencias porcentuales más elevadas se aprecian entre los grupos monolingüe y bilingüe en un modelo de actuación que podría hacer pensar en una mayor inclinación hacia el empleo del sistema referencial por parte de los primeros; los hablantes bilingües, por el contrario, influidos quizá por la presencia del sistema pronominal catalán en su competencia lingüística, mostrarían -aunque sin mucho éxito en términos absolutos- un grado ma- 
yor de conservación del sistema etimológico. Sin embargo, el rigor que la estadística debe imponer a toda investigación sociolingüística nos advierte de nuevo acerca de la adopción de conclusiones apresuradas, por atractivas que aparezcan a primera vista. Cabe dentro de lo posible que en el análisis de otra muestra de la población estudiada los datos permitirían confirmar tales conclusiones, pero ello no ocurre con la nuestra. Aunque es preciso reconocer que en el presente caso, a diferencia de los anteriores, el umbral de significación de los estadísticos de probabilidad está más cerca de los niveles aceptados comunmente, éste (Nivel P 10) sigue cayendo fuera de lo científicamente relevante. Por lo tanto, podemos descartar también la relación de causalidad entre el carácter monolingüe o bilingüe de la competencia lingüística de los hablantes y la inclinación preferencial hacia uno $u$ otro sistema pronominal.

\subsection{Test de complementación}

Como anunciamos más arriba, hemos creído conveniente completar el análisis de esta variable lingüística mediante la introducción de otro registro en la obtención de los datos, siguiendo para ello los planteamientos que sobre el concepto de variación estilistica ha hecho famosa la tradición laboviana. Para ello, nos hemos servido de una técnica formal como el test de complementación, prueba en la que con la excusa de preservar la coherencia textual en un breve párrafo, los informantes deben completar una serie de espacios en blanco con las variables objeto de estudio (Anejo 3 ) $^{20}$.

Además de comprobar la hipotética influencia de este factor contextual en la distribución de las variantes del fenómeno linguiístico estudiado, deseamos analizar también si es posible observar diferencias significativas entre el grado

20 En nuestro caso, no puede decirse tajantemente que los datos obtenidos mediante esta prueba se correspondan enteramente con los de un registro claramente formal, ya que las condiciones en que la llevamos a cabo ocultaban el verdadero objetivo del experimento. Por un lado, el ejercicio no fue realizado directamente por nosotros, sino por un psicólogo del centro, lo que, es de imaginar, supondría una menor presión normativa para los informantes. Por otro, el texto objeto de experimentación presentaba otros items para completar aparte de los que aquí nos interesaban, circunstancia que probablemente disimularía también nuestras intenciones últimas. Pese a ello, la mayor atencion concedida por los hablantes a su mensaje despeja cualquier duda acerca del carácter más formal de los datos obtenidos mediante esta prueba en relación con los anteriores. 
de leismo que presentan algunos verbos. En la Tabla de valores n. 2 (Anejo 1) aparecen las frecuencias absolutas y relativas obtenidas por tres verbos con diferente rendimiento funcional en el habla, como son «ver», «abrazar» y «retener» ${ }^{21}$.

\section{CUADRo 2}

Correlación variable «leísmo/persona/clase de verbo)

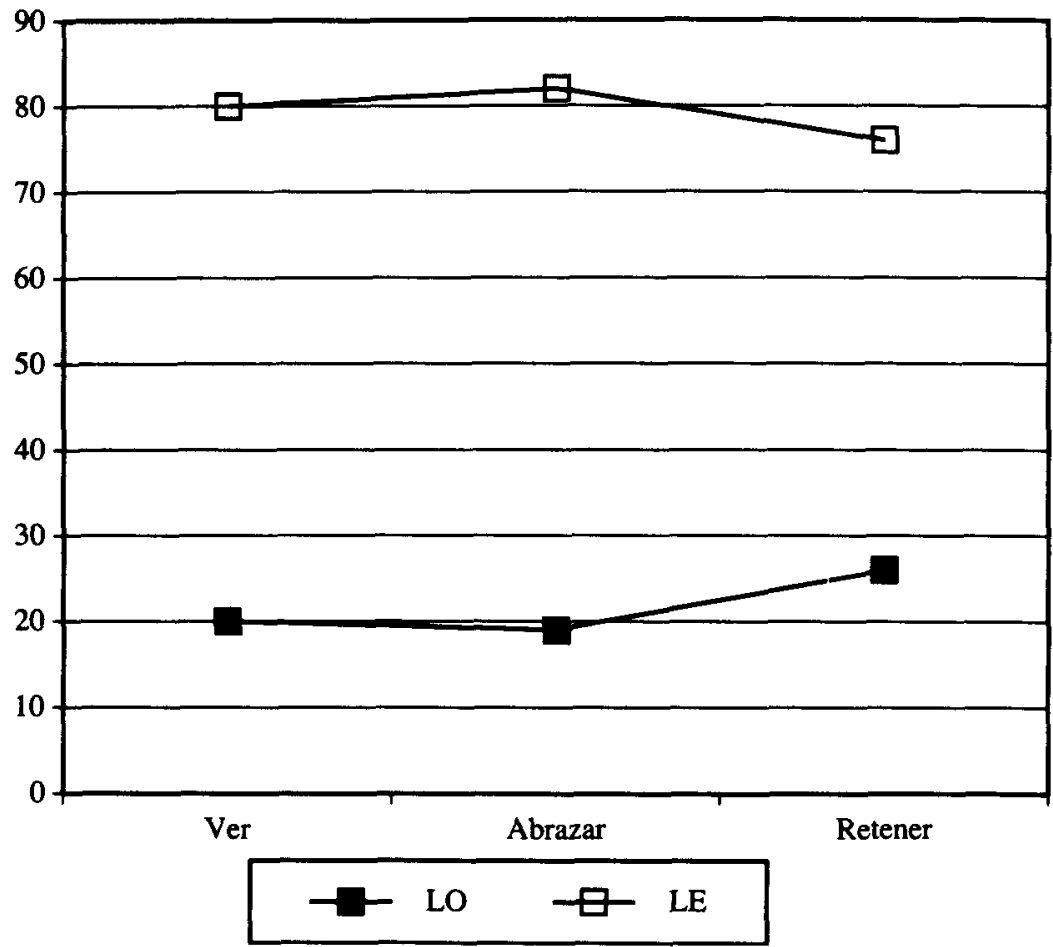

21 Parece evidente que el primero de ellos (ver) ocuparia el primer lugar en esa escala, seguido por abrazar, para concluir con el verbo retener, probablemente el menos habitual en el discurso oral. 
Como se desprende de los datos generales de dicha tabla, parece claro que el nivel de estilo más formal introducido en esta fase del trabajo empírico no ha aportado apenas diferencias con respecto a los datos del habla real. Los porcentajes globales de cada variante son muy similares a los observados en la prueba anterior, oscilando los niveles de leísmo en todos los casos entre el 75 y el $80 \%$ -frente al $79 \%$ anterior-. Ello, además de refutar la posible incidencia de la variación estilística en nuestro caso, nos confirma en la idea de que el llamado leísmo de persona es realmente un fenómeno muy extendido en estas comunidades de habla levantinas, contrariamente a lo que se venía suponiendo.

Por lo que se refiere, finalmente, al segundo de los objetivos, debemos optar también por rechazar la hipótesis planteada inicialmente. Si bien se aprecia un menor grado de leísmo en el verbo de menor rendimiento funcional -retener-, no se puede decir que exista una gradación simétrica en los otros dos -l primero de la escala, ver, ofrece un grado de leísmo ligeramente inferior incluso al del segundo-, además del hecho estadísticamente definitivo de que los umbrales de significación ofrecidos tanto por el análisis de varianza como por el test $t$ - descartan cualquier intento de rechazar la hipótesis nula (valor P 7706; ver Anejo 1).

Igualmente debidas al azar parecen las diferencias porcentuales obtenidas por los distintos grupos sociales de la muestra, por lo que no nos detenemos en su descripción (Anejo 1).

\section{REALIZACIONES Y DISTRIBUCIÓN DE LOS PRONOMBRES LO/LE OBJETO DIRECTO NO PERSONAL MASCULINO (LEFSMO/COSA)}

Como muestra la Tabla de valores n. ${ }^{2} 1$ (Anejo 1), el empleo pronominal en este contexto se atiene absolutamente al esquema normativo etimológico, por lo que puede concluirse que el llamado leísmo de cosa carece por completo de vitalidad en nuestra comunidad de habla. La comparación entre los datos obtenidos en las variables leísmo/persona y leísmo/cosa por medio del análisis de varianza y el test - $t$ es muy significativa (nivel de confianza superior al 91 por $1.000-$ Anejo 2-), lo que permite establecer una división tajante entre ambas. El único informante que hizo un uso antietimológico de lo para la expresión del complemento directo de cosa fue un joven procedente de la ciudad de Madrid y por tanto exclusivamente monolingüe. Sin embargo, esta cifra es tan poco relevante que los análisis probabilísticos no permiten inferir, a partir de la muestra analizada, la presencia de diferencias significativas entre los diferentes grupos sociales (Cuadro 3 ). 


\section{CuAdro 3}

Correlación variable «leísmo/cosa»/variables sociológicas

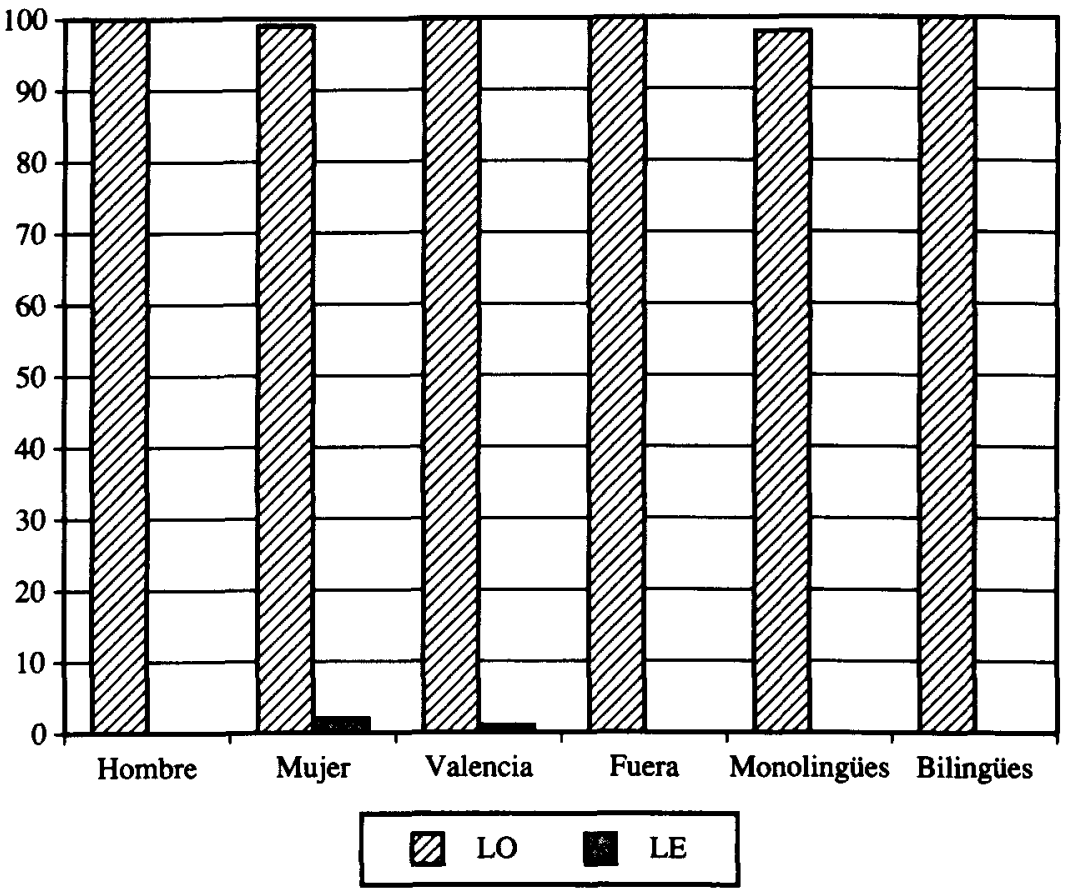

7. REALIZACIONES Y DISTRIBUCIÓN DE LOS PRONOMBRES LEILA . OBJETO INDIRECTO DE PERSONA FEMENINO (LAISMO)

Por lo que se refiere a la variable lingüística que hemos denominado laísmo, hay que indicar que la muestra analizada realiza también un uso ajustado a la distinción casual normativa con una frecuencia muy superior al empleo referencial. Las cifras de este último apenas alcanzan un $10 \%$, frente a un 89 '3\% de los empleos etimológicos, diferencias totalmente significativas a partir del volumen de datos analizados (valor $P$ del 0005 ; véase Anejo 1). Por tanto, la 
estadística permite inferir que en la población estudiada, hay un claro predominio del uso etimológico de los pronombres para la expresión del objeto indirecto femenino, en clara oposición al modelo geolinguístico descrito en otras comunidades de habla del centro de España.

El análisis sociolingüístico ayuda en el presente caso a confirmar el esquema descrito en el párrafo anterior (véase cuadro 4). De las tres variables sociológicas consideradas en el estudio, es la procedencia geográfica de los informantes la que, cuantitativamente, mejor explica la variabilidad en el uso pronominal. En efecto, frente a un $93,5 \%$ de la población autóctona que realiza un uso normativo, un porcentaje significativamente inferior, el $66,6 \%$, corres-

\section{CuAdro 4}

Correlación variable «laísmo/variables sociologicas»

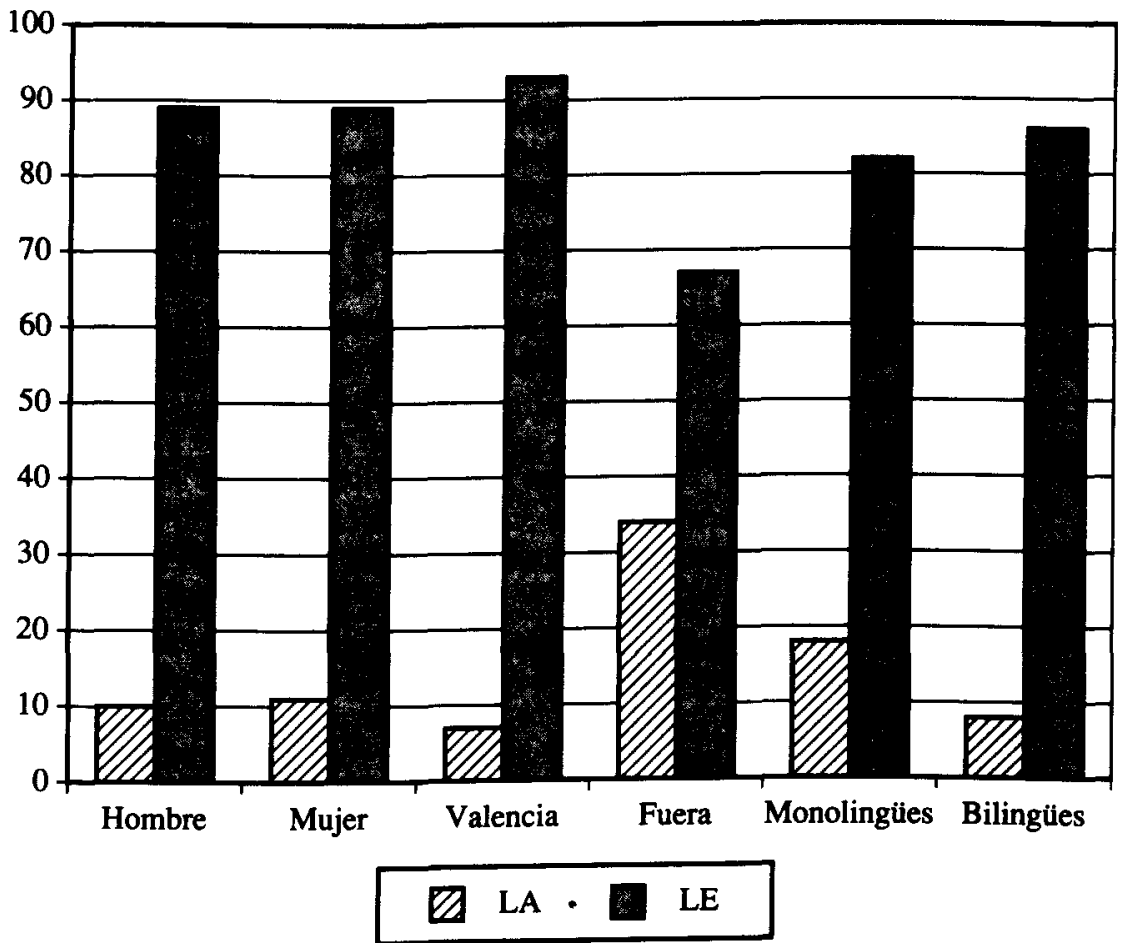


ponde a estos mismos empleos entre la población inmigrante. Si recordamos, además, la procedencia castellana de muchos de estos hablantes, pensamos que existen suficientes argumentos para creer en la incidencia positiva del factor origen en la distribución social de las formas pronominales en el presente contexto sintáctico. Los diferentes patrones de comportamiento sociolingüístico entre ambos grupos son corroborados, además, por los test de probabilidad estadística, cuyos datos arrojan un nivel de confianza del $96 \%$, cifra superior a los umbrales de significación comúnmente aceptados.

Por el contrario, y en consonancia con lo mostrado en las otras dos variables lingüísticas analizadas, los factores sexo y competencia lingüística (monolingüe/bilingüe) de los hablantes no introducen signos claros de estratificación sociolingüística, como se desprende de la simple observación del cuadro adjunto donde los grupos representativos de cada una de las variables sociales anteriores ofrecen frecuencias relativas muy similares.

Una vez analizados los datos correspondientes a las tres variables lingüísticas estudiadas en el presente trabajo, y tras comprobar la escasa incidencia de los factores sociales en su distribución sociolingüística, nos interesa averiguar en qué medida dichas variables hacen homogéneo o heterogéneo el comportamiento de la comunidad objeto de estudio. Para ese objetivo son particularmente útiles las técnicas estadísticas que miden el grado de interdependencia existente entre diferentes variables, es decir, hasta qué punto se hallan relacionadas en una determinada población (Moreno Fernández, 1990: 146). De entre las más conocidas y utilizadas en la investigación social se encuentra el llamado «coeficiente de correlación lineal de Pearson» $(r)$, calculado en nuestro caso a partir de las frecuencias relativas obtenidas por las variantes no normativas de cada una de las variables linguísticas (véase la Tabla de valores $n .^{2} 1$ ). En la siguiente matriz de correlaciones se detallan los coeficientes $r$ de los distintos grupos sociológicos con cada uno de los demás.

Pearson Correlation Matrix

\begin{tabular}{|l|r|r|r|r|r|}
\hline & Hombre & Mujer & Valencia & Fuera & Monoling \\
\hline HOMBRE & 1.000 & & & & \\
MUJER & 1.000 & 1.000 & & & \\
VALENCIA & 998 & 999 & 1.000 & & \\
FUERA & 953 & 945 & 930 & 1.000 & \\
MONOLING & 999 & 998 & 994 & 966 & 1.000 \\
BILING & 999 & 1.000 & 999 & 942 & 997 \\
\hline
\end{tabular}


Como puede apreciarse inmediatamente, el grado de interdependencia entre los distintos grupos sociales que componen la muestra es muy elevado, lo que da idea de un comportamiento sociolingüístico muy homogéneo entre la población estudiada, datos que concuerdan, además, con las diferencias poco significativas que tuvimos ocasión de apreciar en los apartados anteriores. Este comportamiento similar entre los grupos se traduce en la aparición de unos índices superiores siempre al 900 , destacando por la correlación más alta los pares hombre-mujer -1.000 - y mujer-bilingüe - 1.000 - Frente a ellos, y como correlación más bajas destaca el par Valencia-Fuera -930- A pesar de lo elevado de esta última cifra en términos absolutos, el hecho de que se nos presente como la correlación más baja resulta significativo, especialmente si recordamos cómo las diferencias entre ambos grupos en alguna variable lingüística —el laísmo-entraban dentro de los umbrales de confianza estadísticamente válidos.

\section{EVALUACIÓN SOCIAL DE LAS VARIABLES LINGÜISTICAS}

Como anunciamos al principio, nuestro objetivo en este trabajo no radica sólo en la comprobación del grado de extensión social de las variables lingüísticas estudiadas. Continuando una línea teórica y metodológica de gran tradición e interés en la sociolingüística general e hispánica ${ }^{22}$, pretendemos analizar a continuación el grado de aceptación subjetiva de dichas variables. El interés por conocer esta clase de datos se deriva de la importancia que generalmente se concede a los factores actitudinales en el estudio de la variación y el cambio lingüístico. Complementariamente, la comparación entre tales actitudes subjetivas hacia los fenómenos lingüísticos y el grado de realización real de éstos en los contextos menos formales suele interpretarse además como medida de la seguridad o inseguridad lingüistica de los hablantes.

Para la realización de este análisis hemos acudido a una de las pruebas más conocidas, el test de aceptabilidad, con el que se pide a los hablantes que evalúen positiva o negativamente, según su criterio normativo, las diferentes variantes en que aparece dividida una variable lingüística (Anejo 4) ${ }^{23}$.

22 Recuérdense a este respecto los decisivos trabajos de LOPEZ MORALEs sobre el español de Puerto Rico, en los que, a partir del análisis de las variables sociolingúísticas, se abordan cuestiones actitudinales como la seguridad o las creencias lingüísticas.

23 Advertimos que de las tres variables lingüísticas estudiadas en el presente trabajo, tan sólo ofrecemos los datos de las que hemos denominado laísmo y leismo/persona. Al igual que en las fa- 
Del estudio de la variable leísmo/persona, cuyos datos aparecen en la Tabla de valores $n .^{9} 3$ (Anejo 1), se derivan las siguientes conclusiones principales:

1. El análisis de frecuencias general sobre la valoración subjetiva que se hace de las dos variantes - lo/le - revela una aceptación más positiva hacia el uso del pronombre $l e-57,2 \%$ - frente a un $42,8 \%$ que se muestra más favorable a lo. Este dato avala la notable extensión social de que goza actualmente el fenómeno del leísmo de persona en el seno de la comunidad estudiada, hecho que pudimos comprobar también en las dos fases anteriores del trabajo experimental. En definitiva, ello significa que, en el estadio actual de lengua $-y$ al menos en el estrato generacional joven de nuestra comunidad valenciana-, la mayoría de la población no sólo es leísta en la expresión del objeto directo de persona masculina, sino que también considera globalmente mas positiva esta variante lingüística en detrimento del sistema etimológico de uso, supuestamente tradicional en esta área geográfica.

2. Ahora bien, un análisis más detenido de los datos debe hacernos matizar las conclusiones anteriores. En primer lugar, las diferencias porcentuales entre ambas variantes en este experimento y las ofrecidas en los dos contextos anteriores son mucho menores, lo que parece indicar que, al menos una parte de la población que usa la variante lésta o no cree que sea la más aceptable desde un punto de vista normativo o duda sobre ello. En segundo lugar, hay que decir que los datos anteriores se obtuvieron tras la suma global de los resultados obtenidos en cada una de las cuatro frases que fueron objeto de evaluación. Esa suma otorga efectivamente un mayor índice de aceptabilidad de le, pero los resultados son distintos si consideramos aisladamente cada uno de los items. Como revela el análisis de la última tabla de valores mencionada, los porcentajes obtenidos en cada frase son favorables casi siempre a la variante con que aparece escrita la frase en cuestión.

Parece lógico pensar que en estos resultados ha podido influir la propia inercia de la forma en que aparecían los datos en el experimento, especialmente por el desinterés o la falta de atención dispensada por algunos de los informantes encuestados. Sin embargo, no creemos que este hecho sea determinante para explicar tales discrepancias. Por el contrario, pensamos que existe en nuestra comunidad un grado considerable de indecisión o inseguridad en torno a cuál de las dos variantes pronominales es la más adecuada desde una óptica norma-

ses previas del análisis sociolingüístico, la otra variable - leismo/cosa- apenas ha ofrecido interés, dada la casi absoluta unanimidad en tomo al rechazo de la variante leísta entre la población encuestada. 
tiva, inseguridad que sólo se atenúa relativamente si comparamos las frecuencias de cada una en los distintos enunciados ${ }^{24}$.

3. A diferencia de los registros anteriores, la sociolingüística, o mejor la diferenciación social de la comunidad a partir de determinados factores externos, sí tiene ahora una fuerza explicativa considerable (cuadro 5).

\section{Cuadro 5}

Correlación variable «leísmo/persona»/variables sociales (aceptabilidad)
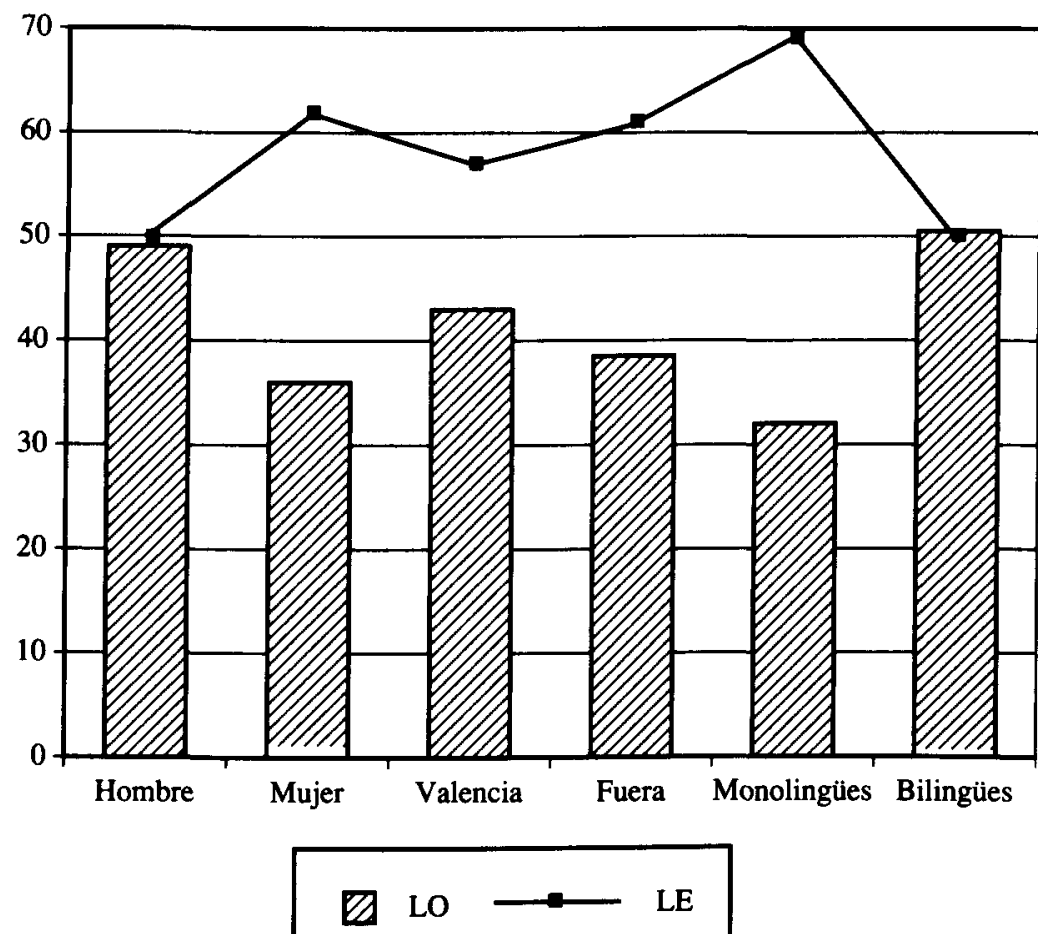

24 Asf ocurre, en efecto, en las dos últimas frases. Mientras en «Parecía que lo miraba con cara de desprecio un $62,1 \%$ muestra su evaluación positiva por la forma pronominal que ya aparece en el texto - frente al $37,9 \%$ restante que la rechaza - en la oración «A Juan le deslumbro la belleza de María, nada menos que un $93,4 \%$ acepta como correcto el empleo del le expreso, y tan sólo un $6,9 \%$ se inclina por la mayor aceptabilidad de $l o$ en tal contexto. 
3.1. Así ocurre, por ejemplo, con el factor sexo, que introduce un grado importante de variabilidad estadísticamente significativa (Anejo 2): mientras los hombres aparecen divididos casi al $50 \%$ en sus evaluaciones positivas de ambas variantes, las mujeres optan claramente por el empleo de le. Estos resultados coinciden, al menos aparentemente, con ciertas regularidades que una parte de la investigación sociolingüística ha creído hallar en torno al modelo de diferenciación sexual. Se ha dicho, por ejemplo, que las mujeres van por delante en la aceptación de las variedades socialmente más prestigiosas o influyentes (Fasold, 1990: 92), variedades que generalmente coinciden con la norma prescriptiva, pero que en otros casos -y el nuestro puede ser uno de ellos- se desmarcan de ésta, lo que podría indicar que nos hallamos ante un cambio lingüístico en curso. Por ello, el hecho de que en nuestra comunidad sea la variante leísta la más valorada subjetivamente y que las mujeres se inclinen por ella de una forma mucho más clara que los hombres, puede encontrar una explicación adecuada a la luz de esta hipótesis sociolingüística. Ahora bien, como contrapartida habría que recordar que las diferencias en el uso real de esta variable linguíistica fueron escasas y poco significativas entre los grupos masculino y femenino. Finalmente, la comparación entre los datos del test de aceptabilidad y los de uso real sugieren una mayor inseguridad lingüística de los hablantes masculinos, a diferencia del grupo de mujeres, más homogéneas entre lo que dicen y lo que consideran correcto.

3.2. Todavía en mayor proporción que el factor sexo, la variable no estructural competencia (monolingüe/bilingüe) se ha revelado como significativamente relevante para explicar la variabilidad en materia de actitudes hacia las variables lingüísticas (Anejo 2). Se trata, incluso, del único caso en que un grupo sociológico —l de hablantes bilingüe- supera el porcentaje de actitudes favorables a la variante $l o$ frente a $l e-50$ ' $9 \%$ frente a $49^{\prime} 1 \%$-, cifra ciertamente no significativa en términos absolutos, pero sí bastante más si la comparamos con la que ofrece el grupo de monolingües castellano-hablantes, mayoritariamente inclinados hacia el uso leísta.. La mayor inseguridad lingüística de los hablantes bilingües puede venir provocada por el conflicto entre unos usos sociales claramente favorecedores del leismo de persona y una competencia linguiística híbrida en la que la mayor ortodoxia etimológica del otro sistema lingüístico en contacto representa quizá un freno para el triunfo definitivo de aquél, al menos en el terreno de las actitudes. Recuérdese a este respecto que, pese a que las diferencias frecuenciales en la prueba de uso real no llegaron a conseguir un grado de significación suficientemente aceptable -aunque tampoco estuvo muy lejos de él一, también fue entonces el grupo de monolingües castellano-hablantes el más inclinado hacia las soluciones leístas. 
3.3. Frente a los dos factores sociales considerados hasta el momento, la variable origen no aporta diferencias sociolingüísticas destacables entre sus dos grupos. Aunque las distancias porcentuales son favorables al grupo de inmigrantes en relación con la aceptabilidad de la variante leísta -61 '5\% frente a 56'3\% del grupo de hablantes nacido en Valencia-, éstas son escasas y en cualquier caso, no significativas estadísticamente a la luz de la muestra analizada, tal como revelan los test probabilísticos utilizados en la investigación (Anejo 2).

Para cerrar este capítulo dedicado a la evaluación social de las variables lingüísticas ofrecemos también algunos datos sobre la variable laísmo.

\section{CuAdro 6}

Correlación variable «laísmo»/variables sociales (aceptabilidad)
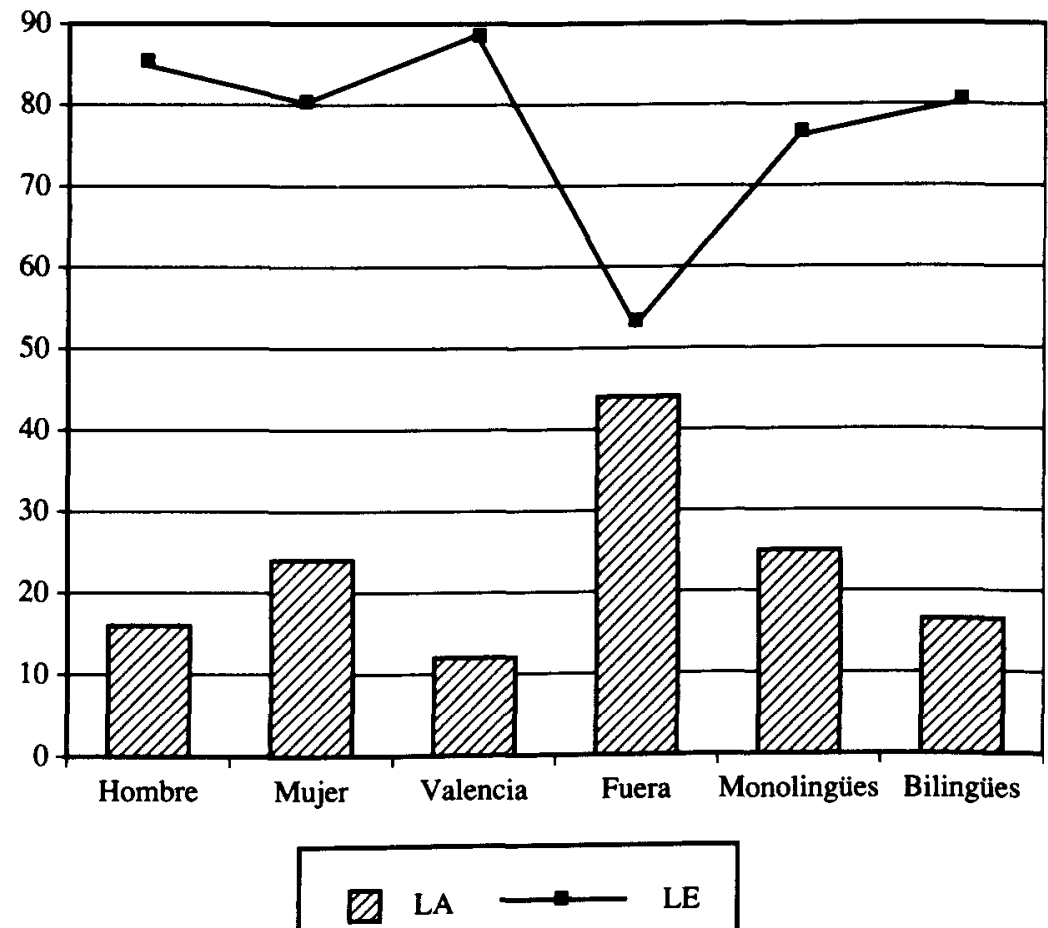
Como muestra el cuadro anterior, la consideración subjetiva de la variante laísta en el conjunto de la población estudiada es claramente negativa. El porcentaje global del $82 \%$ de valoraciones negativas revela que estamos en presencia de una variante lingüística claramente estigmatizada, hecho que concuerda, además, con los datos del habla real, de ahí que el grado de inseguridad lingüística del conjunto de la comunidad sea en este caso -como en el del leísmo de cosa- muy pequeño. Por otro lado, también en este caso observamos el dato discrepante de los hablantes nacidos fuera de Valencia, principalmente - recuérdese- del centro de España. Si en la prueba de uso real ofrecían ya algunas muestras de laísmo, de nuevo estos hablantes sobresalen por encima del resto en la actitudes menos negativas hacia un rasgo que deben intuir fuera de su contexto geolectal más adecuado, pero por el que manifiestan todavía cierto apego.

\section{CONCLUSIONES}

De los datos aportados por nuestra investigación se desprende que las hipótesis sobre la realización y la distribución social de los pronombres átonos de tercera persona en el área geográfica valenciana sólo se ven confirmadas en parte. No obstante las escasa noticias que existían sobre el uso de tales pronombres en estas comunidades de habla bilingües, los datos manejados hasta la fecha venían a coincidir en la práctica ausencia de fenómenos como el leísmo de cosa o el laísmo, hechos que han sido confirmados efectivamente en nuestro caso a través del análisis sociolinguíístico. En el caso del laísmo, incluso, la comparación entre los datos aportados por los hablantes nacidos en Valencia y los inmigrantes oriundos de regiones del centro de España ha contribuido a circunscribir claramente el ámbito geolingüístico del fenómeno y a descartarlo como rasgo característico del español de Valencia.

Lo anterior, sin embargo, contrasta sobremanera con las características de la otra variable lingüística analizada en el trabajo. En efecto, y frente a una cierta unanimidad apriorística nunca del todo confirmada, se ha dicho que el empleo de los pronombres para la expresión del objeto directo en las regiones bilingües del Levante español sigue generalmente el patrón etimológico, todavía hoy modelo preceptivo en el mundo hispánico, al margen de la permisividad con el llamado leismo de persona masculino en ciertas regiones peninsulares. Sin embargo, ni siquiera el reconocimiento esporádico de que también este leísmo aparece ocasionalmente en nuestras regiones bilingües, sirve para ate- 
nuar el contraste entre este panorama geolingüístico y el que se desprende de nuestra investigación. Y es que, en efecto, las soluciones leístas para la expresión del O.D. masculino de persona son claramente mayoritarias en nuestra comunidad de habla, en detrimento de la variante etimológica - lo-_, supuestamente más representativa de esta área geolectal.

El panorama general de esta variable lingüística expuesto en el párrafo anterior se ve confirmado por una serie de datos complementarios. En primer lugar, las diferencias porcentuales entre las variantes leístas y las no leístas son muy abultadas -79 '9 frente a $21,1 \%$ respectivamente - . Por otro lado, la aplicación de otras pruebas para medir el uso de esta variable en contextos de mayor formalidad, y por lo tanto, en contextos donde la conciencia lingüística y la atención del hablante hacia su habla es mayor, han arrojado asimismo unos resultados claramente favorables a la solución leísta ${ }^{25}$. Finalmente, podemos afirmar que el comportamiento de la sociedad en torno a esta variable es bastante homogéneo, al menos en el habla espontánea, como se desprende de la ausencia de distancias estadísticamente relevantes entre los diferentes grupos sociológicos analizados.

A la vista de los datos anteriores creemos poder concluir que el leísmo de persona es un fenómeno gramatical de una fuerte vitalidad social en nuestra comunidad. Ahora bien, el hecho de que nuestra investigación se haya centrado en un sólo estrato generacional, el más joven, no nos permite ir más allá en nuestras conclusiones sobre el conjunto de la sociedad. La perspectiva de que estemos asistiendo a una de las etapas - desconocemos en qué punto- de un cambio lingüístico en marcha, esto es, a un innovación que desde el sistema etimológico tradicional en estas regiones pasa a otro sistema, esta vez referencial, podría ser una hipótesis interesante de trabajo para ulteriores investigaciones que aborden el factor generacional de la variación lingüística. En cualquier caso, nuestros datos parecen suficientemente reveladores acerca de la pujanza social del leísmo en la sociedad valenciana. 


\section{REFERENCIAS BIBLIOGRAFICAS}

BadiA I MARGARIT, A. (1962/85): Gramática catalana, vol. II, Madrid, Gredos.

BeLLo, A. (1847/1964): Gramática de la lengua castellana, Buenos Aires, Sopena.

BLAS ARROYO, J. L. (1992): Rasgos interferenciales en el español de una comunidad bilingüe, Liria, Exmo. Ayuntamiento de Liria.

- (1993): La interferencia lingüistica en Valencia (dirección: catalán-castellano). Estudio sociolingüistico, Castellón, Publicaciones de la Universitat Jaume I.

CuERVo, R. J. (1895): «Los casos enclíticos y proclíticos del pronombre de tercera persona en castellanow, Romania, XXIV, pp. 95-113 y 219-63.

ECHENIQUE, M. (1981): «El sistema referencial en español antiguo», RFE, LXI, pp. 113-57.

FERNÁNDEZ RAMIREZ, S. (1951): Gramática española. Los sonidos, el nombre y el pronombre, Madrid, Manuales de la Revista de Occidente.

- (1964): «Un proceso lingǘrtico en marchaw, en Presente y Futuro de la lengua española, Madrid, Instituto de Cultura Hispánica, II, pp. 277-85.

GARCfA, E. (1975): The Role of Theory in Linguistic Analysis: The Spanish Pronoum System, North-Holland, Linguistic Series.

GARCIA GONZALEZ, F. (1978): «El leísmo en Santanderw, en Estudios ofrecidos a Emilio Alarcos Llorach, III, Oviedo, pp. 87-101.

GessNer, R. (1893): «Das spanische Personalpronomen», Zeitschrift für Romaische Philologies, XVII, pp. 5-7. 
GILI GayA, S. (1958): Curso superior de sintaxis española, Barcelona, Spes.

KLEIN, F. (1979): «Factores sociales en algunas diferencias lingüísticas en Castilla la Vieja», Papers: Revista de Sociología, 11, pp. 45-64.

- (1981): «Distintos sistemas de empleo de "le", "la", "lo". Perspectiva sincrónica, diacrónica y sociolinguística", Thesaurus Boletín Instituto Caro y Cuervo, XXXVI, pp. 284-304.

LABOV, W. (1972/83): Modelos sociolingüistiros, Madrid, Cátedra.

LAMfQuiz, V. (1976): «Sociolingüística en una habla urbana: Sevilla», RSEL, 6.2, pp. 345-62.

LAPESA, R. (1968): «Sobre los orígenes y evolución del leísmo, laísmo y loísmo», en Festchrift W. v. Wartburg, I, Tübingen, Max Niemayer, pp. 523-551.

LOPEZ MORALES, H. (1989): Sociolingüística, Madrid, Gredos.

LoRENzo RAmos, A. (1981): «Algunos datos sobre el leísmo, laísmo y ló́smo», I Simposio Internacional de Lengua Española, Las Palmas, Gran Canaria.

LloRENTE Maldonado, A. (1980): «Consideraciones sobre el español actual», Anuario de Letras, XVIII, Méjico, pp. 5-61.

MARCOS MARÍN, F. (1978): Estudios sobre el pronombre, Madrid, Gredos.

MARTINEZ MARTín, M. (1984): «Datos sobre el leísmo y el laísmo de persona en el habla de la ciudad de Burgos», Epos, I, Madrid, pp. 159-176.

MONGE, F. (1983): «Notas a una hipótesis sobre el leísmo», en Serta Philologica F. Lazaro Carreter, I, Madrid, Cátedra, pp. 441-55.

MORENO FERNÁNDEZ, F. (1990): Metodología sociolingüistica, Madrid, Gredos.

MORENO FERNÁNDEZ, F. Y OTROS (1988): «Anotaciones sobre el leísmo, el laísmo y el loísmo en la provincia de Madrid», Epos, IV, pp. 101-22.

QUILIS, A. Y OTROS (1985): Los pronombres le, la, lo y sus plurales en la lenguas española hablada en Madrid, Madrid, CSIC. 
RoJo, G. (1981): «Conductas y actitudes lingǘsticas en Galicia», RSEL, 11.2, pp. 269-310.

SALVÁ, V. (1830): Gramática de la lengua castellana, París, Librería Hispanoamericana.

SANKOFF, D. (1988/92): «Sociolingüística y variación sintáctica», en Panorama de la Lingüistica Moderna de la Universidad de Cambridge, Vol. IV, F. Newmeyer, F. (ed.), Madrid, Visor.

SCHMIDELY, J. (1972): «Grammaire et statistique: l'altemance le/lo dans l'expression de l'objet pronominal "direct" en espagnol», Études de Linguistique Appliquée, 6, pp. 37-58.

Silva CoRvalÁ, C. (1989): Sociolingüistica. Teoría y análisis, Madrid, Alhambra Universidad.

STAAF, E. (1906): Etude sur les pronoms abrégés en ancien espagnol, Upsala y Leipzig.

TRINIDAD, F. (1969): Arniches. Un estudio del habla popular madrileña, Madrid, Góngora. 


\section{ANEJO 1: \\ TABLAS DE FRECUENCIAS}

\section{Tabla 1}

\section{LINGÜISTICAS}

\begin{tabular}{|c|c|c|c|c|c|c|c|}
\hline V. sociales & $\begin{array}{c}\text { Leismoipersona } \\
\text { (lo) }\end{array}$ & $\begin{array}{c}\text { Letsmoipersona } \\
\text { (le) }\end{array}$ & $\begin{array}{l}\text { Letsmo/cosa } \\
\text { (bo) }\end{array}$ & $\begin{array}{c}\text { Leísmo/cosa } \\
\quad(l e)\end{array}$ & $\begin{array}{l}\text { Laismo } \\
\text { (la) }\end{array}$ & \multicolumn{2}{|c|}{$\begin{array}{c}\text { Laismo } \\
\text { (le) }\end{array}$} \\
\hline & $27 \quad(23,5 \%)$ & $88(76,5 \%)$ & $(0 \%)$ & $41(100 \%)$ & $5(10,4 \%)$ & 43 & \\
\hline & $25 \quad(19 \%)$ & & $1(2,1 \%)$ & $46(97,9 \%)$ & $7(10,9 \%)$ & 57 & (89, \\
\hline & $41 \quad(21,1 \%)$ & $153(78,9 \%)$ & $1 \quad(1,4 \%)$ & $69(98,6 \%)$ & $6(6,5 \%)$ & 85 & (93, \\
\hline & $11(21,1$ & & $\begin{array}{ll}0 & (0 \%)\end{array}$ & $18 \quad(10$ & $7(33,3 \%)$ & 14 & $(66$ \\
\hline & $19(16$ & & $1 \quad(2,5 \%)$ & $39(97,5 \%)$ & $7(17,1 \%)$ & 34 & (82, \\
\hline Bilingüe & $34(76,3 \%)$ & $109(76,3 \%)$ & $0 \quad(0 \%)$ & $51(100 \%)$ & $5(7,6 \%)$ & 60 & (85, \\
\hline
\end{tabular}

Tabla 2

V. LINGÜISTICA «LEISMO/PERSONA»/CLASE DE VERBO

\begin{tabular}{|c|c|c|c|c|c|c|c|}
\hline & Hombre & Mujer & Valencia & Fuera & Monolingüe & \multicolumn{2}{|c|}{ Bilingüe } \\
\hline Verlo & $9(23,7 \%)$ & $7(16,6 \%)$ & $12(19,3 \%)$ & $4(22,2 \%)$ & $8(21,6 \%)$ & 8 & $(17,4$ \\
\hline Verle & $29(76,3 \%)$ & $35(83,4 \%)$ & $50(80,7 \%)$ & $14(77,8 \%)$ & $29(78,4 \%)$ & 38 & $(82$, \\
\hline Lo abrazo & $7(18,4 \%)$ & $8(18,8 \%)$ & $13(20,3 \%)$ & $2(11,1 \%)$ & $4(10,8 \%)$ & 12 & $(25$, \\
\hline Le abrazó & $31 \quad(81,6 \%)$ & $36(81,1 \%)$ & $51(79,7 \%)$ & $16(88,9 \%)$ & $34(89,1 \%)$ & 35 & $(74$ \\
\hline Lo retuvo & $11 \quad(28,2 \%)$ & $10(22,2 \%)$ & $16(23,5 \%)$ & $5(31,2 \%)$ & $7(18,9 \%)$ & 14 & (28 \\
\hline Le retuvo & $28 \quad(71,8 \%)$ & $35(77,8 \%)$ & $52(76,5 \%)$ & $11(68,8 \%)$ & $30(81,1 \%)$ & 36 & $(72$ \\
\hline
\end{tabular}




\section{Tabla 3}

\section{LINGÜISTICAS (ACEPTABILIDAD)}

\begin{tabular}{|c|c|c|c|c|c|c|c|c|}
\hline & \multicolumn{2}{|c|}{ Hombre } & Mujer & Valencia & Fuera & Monolingüe & \multicolumn{2}{|c|}{ Bilingüe } \\
\hline Le dijo & & $(84,5 \%)$ & $36(78,3 \%)$ & $58(87,8 \%)$ & $10(55,5 \%)$ & $29(76,3 \%)$ & 41 & (85, \\
\hline La dijo & & $(15,4 \%)$ & $10(21,7 \%)$ & $8(12,2 \%)$ & $8(44,5 \%)$ & $9 \quad(23,7 \%)$ & 7 & $(14,6$ \\
\hline Lo perseguían & & $(70,7 \%)$ & $34(72,3 \%)$ & $49 \quad(70 \%)$ & $14(77,7 \%)$ & $22 \quad(57,9 \%)$ & 41 & $(80$, \\
\hline Le perseguían & & $(29,3 \%)$ & $13(27,7 \%)$ & $21 \quad(30 \%)$ & $4(22,3 \%)$ & $16(42,1 \%)$ & 10 & (19, \\
\hline Lo asesinaron & & $(39 \%)$ & $11(23,4 \%)$ & $23(32,8 \%)$ & $4(22,3 \%)$ & $7 \quad(17,5 \%)$ & 21 & $(41$, \\
\hline Le asesinaron & & $(61 \%)$ & $36(76,6 \%)$ & $47(67,2 \%)$ & $14(77,7 \%)$ & $31(82,5 \%)$ & 30 & $(58$, \\
\hline Lo miró & & $(72,5 \%)$ & $24 \quad(51 \%)$ & $45(64,3 \%)$ & $8 \quad(50 \%)$ & $18 \quad(47,3 \%)$ & 35 & $(70 \%)$ \\
\hline Le miró & & $(27,5 \%)$ & $23 \quad(49 \%)$ & $25(35,7 \%)$ & $8 \quad(50 \%)$ & $20 \quad(52,7 \%)$ & 15 & (30\%) \\
\hline Lo deslumbró & & $(15 \%)$ & $\begin{array}{ll}0 & (0 \%)\end{array}$ & $5 \quad(7,2 \%)$ & $1 \quad(5,5 \%)$ & $2 \quad(5,2 \%)$ & 6 & $(12 \%)$ \\
\hline Le deslumbró & & $(85 \%)$ & $47(100 \%)$ & $64(92,8 \%)$ & $17(94,5 \%)$ & $36 \quad(94,8 \%)$ & 44 & (88\%) \\
\hline
\end{tabular}




\section{ANEJO 2:}

TEST PROBABILISTICOS (ANÁLISIS DE VARIANZA Y TEST T)

VARIABLE LINGUUISTICA *LEISMO/PERSONA* (VARIANTES: «LO $/ /$ LE»)

\begin{tabular}{|c|c|c|c|c|c|c|}
\hline SOURCE & SUM-OF-SQU & DF & MEAN-SQUARE & F-RATIO & $T$ & NINELP \\
\hline & 19530.062 & 1 & $\begin{array}{c}19530.062 \\
1098.098\end{array}$ & $\begin{array}{c}17.785 \\
-\end{array}$ & $\begin{array}{c}4.217 \\
-\end{array}$ & $\begin{array}{c}0009 \\
-\end{array}$ \\
\hline
\end{tabular}

VARIABLE LINGÜISTICA «LEISMO/COSA» (VARIANTES: «LO»/«LE»)

\begin{tabular}{|c|c|c|c|c|c|c|}
\hline SOURCE & SUM-OF-SQU & DF & MEAN-SQUARE & F-RATIO & $T$ & NIVELP \\
\hline & 6972.250 & 1 & 6972.250 & 37.320 & 6.109 & 0001 \\
ERROR & 2615.500 & 14 & 186.821 & - & - & - \\
\hline
\end{tabular}

VARIABLE LINGUUISTICA «LEISMO/COSA» (VARIANTES: «LO»/«LE»)

\begin{tabular}{|c|c|c|c|c|c|c|}
\hline SOURCE & SUM-OF-SQU & DF & MEAN-SQUARE & F-RATIO & $T$ & NIVELP \\
\hline & 6006.250 & 1 & 6006.250 & 19.909 & 4.462 & 0005 \\
ERROR & 4223.500 & 14 & 301.679 & - & - & - \\
\hline
\end{tabular}


VARIABLE LINGÜISTICA «LEÍSMO/PERSONA»(CORRELACIÓN V. SOCIALES)

\begin{tabular}{|l|c|r|c|c|c|c|}
\hline \multicolumn{1}{|c|}{ SOURCE } & SUM-OF-SQU & \multicolumn{1}{c|}{ DF } & MEAN-SQUARE & F-RATIO & $T$ & NINELP \\
\hline SEXO & $\begin{array}{c}099 \\
\text { ERROR }\end{array}$ & $\begin{array}{r}1 \\
40.998\end{array}$ & $\begin{array}{c}099 \\
167\end{array}$ & 591 & 769 & 442 \\
\hline ORIGEN & $\begin{array}{c}1.612 \mathrm{E}-6 \\
\text { ERROR }\end{array}$ & $\begin{array}{r}1.008 \\
1\end{array}$ & $\begin{array}{c}1.612 \mathrm{E}-6 \\
168\end{array}$ & 9.59 & 003 & 997 \\
\hline COMPET & .354 & 1 & 354 & 2.124 & 1.457 & 146 \\
ERROR & 42.210 & 253 & 167 & & & \\
\hline
\end{tabular}

VARIABLE LINGÜISTICA «LAÍSMO» (CORRELACIÓN V. SOCIALES)

\begin{tabular}{|c|c|c|c|c|c|c|}
\hline SOURCE & SUM-OF-SQU & $D F$ & MEAN-SQUARE & F-RATIO & $T$ & NIVELP \\
\hline $\begin{array}{l}\text { SEXO } \\
\text { ERROR }\end{array}$ & $\begin{array}{r}001 \\
10.714\end{array}$ & $\begin{array}{r}1 \\
110\end{array}$ & $\begin{array}{l}001 \\
097\end{array}$ & 008 & 087 & 930 \\
\hline $\begin{array}{l}\text { ORIGEN } \\
\text { ERROR }\end{array}$ & $\begin{array}{r}619 \\
15.810\end{array}$ & $\begin{array}{r}1 \\
110\end{array}$ & $\begin{array}{l}619 \\
144\end{array}$ & 4.307 & 2.075 & 0403 \\
\hline $\begin{array}{l}\text { COMPET } \\
\text { ERROR }\end{array}$ & $\begin{array}{r}172 \\
13.924\end{array}$ & $\begin{array}{r}1 \\
81\end{array}$ & $\begin{array}{l}172 \\
172\end{array}$ & 1.003 & 1.002 & 319 \\
\hline
\end{tabular}

\section{TEST DE ACEPTABILIDAD}

VARIABLE LINGÜISTICA «LEÍSMO/PERSONA» (CORRELACIÓN V. SOCLALES)

\begin{tabular}{|c|c|c|c|c|c|c|}
\hline SOURCE & SUM-OF-SQU & $D F$ & MEAN-SQUARE & F-RATIO & $T$ & NNEL P \\
\hline $\begin{array}{l}\text { SEXO } \\
\text { ERROR }\end{array}$ & $\begin{array}{r}1.399 \\
84.169\end{array}$ & $\begin{array}{r}1 \\
348\end{array}$ & $\begin{array}{l}1.399 \\
0.242\end{array}$ & 5.785 & 2.405 & 017 \\
\hline $\begin{array}{l}\text { ORIGEN } \\
\text { ERROR }\end{array}$ & $\begin{array}{r}170 \\
85.360\end{array}$ & $\begin{array}{r}1 \\
347\end{array}$ & $\begin{array}{l}170 \\
246\end{array}$ & 692 & 832 & 406 \\
\hline $\begin{array}{l}\text { COMPET } \\
\text { ERROR }\end{array}$ & $\begin{array}{r}9.270 \\
78.704\end{array}$ & $\begin{array}{r}1 \\
350\end{array}$ & $\begin{array}{r}9.270 \\
225\end{array}$ & 41.226 & 6.421 & 000 \\
\hline
\end{tabular}


VARIABLE LINGÜISTICA «LAfSMO» (CORRELACIÓN V. SOCIALES)

\begin{tabular}{|l|c|c|c|c|c|c|}
\hline \multicolumn{1}{|c|}{ SOURCE } & SUM-OF-SQU & \multicolumn{1}{c|}{ DF } & MEAN-SQUARE & F-RATIO & $T$ & NIVELP \\
\hline SEXO & $\begin{array}{c}0.085 \\
\text { ERROR }\end{array}$ & $\begin{array}{r}1 \\
12.903\end{array}$ & $\begin{array}{l}0.085 \\
0.155\end{array}$ & 548 & 1.254 & 461 \\
\hline ORIGEN & 763 & 1 & 763 & 4.045 & & 048 \\
ERROR & 15.475 & 82 & 189 & & & \\
\hline ORIGEN & 451 & 1 & 451 & 6.337 & & 014 \\
ERROR & 5.979 & 84 & 071 & & & \\
\hline
\end{tabular}




\section{ANEJO 3: \\ TEST DE COMPLEMENTACION}

Alfonso estaba dentro hablando con Elena. decía que uno de sus entretenimientos favoritos era recorrer el río en barco.

Más tarde, y ya fuera del salón, Alfonso parecía vigilar la puerta de Juan, el hermano de Elena. Al ver salir, fue a encuentro y abrazó amistosamente. En aquel instante.

En aquel instante, Juan pudo haber regresado a la pensión, pero el temor que sentía retuvo. A Elena, sin embargo, no hubiera gustado comprobar que hermano. Una vez en el salón, Alfonso recogí el libro que estaba leyendo $y$ depositó en la librería. 


\title{
ANEJO 4: \\ TEST DE ACEPTABILIDAD
}

\begin{abstract}
A Juana la dije que no viniera.
A Juan todo el mundo lo perseguía para que le resolviera sus problemas.

Al presidente de ese país le asesinaron unos terroristas la semana pasada. El niño no había hecho nada, pero Juan lo miró como si fuera un delincuente.
\end{abstract}

Elena no era muy bonita, pero a Juan le deslumbró por completo.

Coge el libro y ábrele por la página cien. 